\title{
Gambaran Pengetahuan dan Sikap Ibu Hamil dalam Pencegahan Anemia pada Kehamilan di Indonesia
}

\author{
Delviana Devi, ${ }^{1}$ Anastasia M. Lumentut, ${ }^{2}$ Eddy Suparman $^{2}$
}

\author{
${ }^{1}$ Program Studi Pendidikan Dokter Fakultas Kedokteran Universitas Sam Ratulangi, Manado, \\ Sulawesi Utara, Indonesia \\ ${ }^{2}$ Bagian Ilmu Kebidanan dan Kandungan Fakultas Kedokteran Universitas Sam Ratulangi, \\ Manado, Sulawesi Utara, Indonesia \\ Email: delvianad6@gmail.com
}

\begin{abstract}
The level of knowledge and behavior of pregnant women regarding anemia during pregnancy affects how they maintain their pregnancies, therefore, the occurrence of anemia during pregnancy can be prevented. This study was aimed to obtain the knowledge and attitudes of pregnant women in preventing anemia in pregnancy in Indonesia. This was a literature review study by using four databases, as follows: Pubmed, ClinicalKey, ScienceDirect, and Google Scholar. Keywords used were anemia AND pregnant woman AND knowledge OR attitude AND Indonesia in Pubmed, ClinicalKey, and ScienceDirect; and anemia AND pregnant women AND knowledge AND attitudes in Google Scholar. There were 11 literatures selected in this study. According to the knowledge of pregnant women about anemia, five literatures showed that the majority of pregnant women had sufficient knowledge, the other four literatures showed poor knowledge, while good knowledge was obtained in two literatures. According to attitude, seven studies got positive attitudes, three studies got negative attitudes, and one study got the same number of positive and negative attitudes. In conclusion, the majority of pregnant women in several regions in Indonesia have sufficient knowledge about anemia and its prevention, and have a positive attitude towards anemia prevention in pregnancy.
\end{abstract}

Keywords: knowledge, attitudes, pregnant women, anemia.

\begin{abstract}
Abstrak: Tingkat pengetahuan dan perilaku ibu hamil mengenai anemia saat kehamilan berpengaruh terhadap cara ibu hamil menjaga kehamilannya sehingga dapat membantu dalam mencegah anemia selama kehamilan. Penelitian ini bertujuan untuk mengetahui gambaran pengetahuan dan sikap ibu hamil dalam pencegahan anemia pada kehamilan di Indonesia. Jenis penelitian ialah literature review dengan pencarian literatur menggunakan empat database yaitu Pubmed, ClinicalKey, ScienceDirect dan Google Scholar. Kata kunci yang digunakan yaitu anemia AND pregnant woman AND knowledge OR attitude AND Indonesia pada Pubmed, ClinicalKey, dan ScienceDirect, dan menggunakan kata kunci anemia AND ibu hamil AND pengetahuan AND sikap pada Google Scholar. Hasil seleksi mendapatkan 11 literatur yang diteliti. Hasil penelitian mendapatkan bahwa menurut pengetahuan ibu hamil mengenai anemia, lima penelitian menunjukkan mayoritas ibu hamil memiliki pengetahuan cukup, empat literatur lainnya menunjukkan hasil pengetahuan buruk, sedangkan hasil pengetahuan baik didapatkan pada dua penelitian. Menurut sikap, tujuh penelitian mendapat hasil sikap positif, tiga penelitian mendapat hasil sikap negatif, dan satu penelitian mendapat hasil yang sama banyak untuk positif dan negatif. Simpulan penelitian ini ialah mayoritas ibu hamil di beberapa daerah di Indonesia memiliki pengetahuan cukup mengenai anemia dan pencegahan, serta memiliki sikap positif terhadap pencegahan anemia pada kehamilan.
\end{abstract}

Kata kunci: pengetahuan, sikap, ibu hamil, anemia 


\section{PENDAHULUAN}

Masa kehamilan merupakan hal yang harus diperhatikan, karena termasuk dalam 1.000 hari kehidupan. Ibu hamil merupakan salah satu kelompok rawan gizi. Asupan gizi ibu hamil sangat berpengaruh pada perkembangan janin. Status gizi yang baik pada ibu hamil dapat mencegah terjadinya berat bayi lahir rendah (BBLR) dan stunting (pendek). ${ }^{1}$

World Health Organization (WHO) memperkirakan bahwa pada $42 \%$ anak di bawah 5 tahun dan $40 \%$ wanita hamil menderita anemia. ${ }^{2}$ Kurang lebih terdapat 370 juta wanita di negara berkembang menderita anemia defisiensi zat besi $41 \%$ di antaranya ialah wanita hamil. ${ }^{3}$

Prevalensi anemia di Indonesia masih cukup tinggi. Data dari Kemenkes RI (2013) menunjukkan angka prevalensi anemia pada semua ibu hamil, secara nasional mencapai $37,1 \%$. Prevalensi anemia berdasarkan daerah menunjukkan bahwa penderita yang tinggal di pedesaan memiliki angka lebih tinggi $(22,8 \%)$ dibandingkan yang tinggal di perkotaan $(20,6 \%)$. Sementara itu, prevalensi anemia pada remaja berusia lebih dari 15 tahun sebesar 22,7\%. Pada tahun 2018, proporsi anemia ibu hamil mencapai $48,9 \%{ }^{3}$

Anemia pada kehamilan dapat memengaruhi pertumbuhan dan perkembangan janin saat kehamilan maupun kelahiran, seperti abortus, terjadi kematian intrauterin, prematuritas, berat badan lahir rendah, retardasi pertumbuhan intrauterin, depresi perinatal, dan kematian perinatal. Selain itu, jika anemia tidak diobati dengan segera, halhal lain yang dapat memengaruhi ibu hamil ialah ancaman payah jantung, ketuban pecah dini, gangguan his, retensio plasenta, perdarahan postpartum karena atonia uteri, hingga kematian ibu akibat persalinan. ${ }^{4,5}$ Wanita hamil sangat rentan mengalami anemia defisiensi besi, karena wanita hamil membutuhkan kadar oksigen lebih tinggi sehingga memicu peningkatan produksi eritropoetin. Akibatnya, volume plasma darah bertambah dan jumlah eritrosit meningkat. Peningkatan volume plasma terjadi dalam proporsi yang lebih besar dari peningkatan eritrosit, sehingga terjadi penurunan konsentrasi hemoglobin $(\mathrm{Hb})$ akibat hemodilusi. ${ }^{6}$ Meskipun terjadi hemodilusi, biasanya tidak berpengaruh pada perubahan mean corpuscular volume (MCV) atau mean corpuscular haemoglobin concentration (MCHC). ${ }^{7}$

Pemberian suplemen zat besi, dengan dosis pemberian sehari 1 tablet berisi $60 \mathrm{mg}$ elemental iron dan $0,25 \mu \mathrm{g}$ asam folat minimal selama 90 hari selama masa kehamilan. Kepatuhan dalam mengonsumsi suplemen zat besi merupakan hal yang harus diperhatikan. ${ }^{8}$ Data dari Kemenkes RI menyebutkan, cakupan pemberian tablet tambah darah (TTD) pada ibu hamil di Indonesia tahun 2018 ialah 73,2\%. Angka tersebut belum mencapai target renstra tahun 2018 yaitu 95\%. Provinsi dengan cakupan tertinggi pemberian tablet tambah darah (TTD) pada ibu hamil yaitu Bengkulu dengan angka 99,94\%, sedangkan provinsi dengan cakupan terendah ialah Banten yaitu $32,11 \%$. Hanya terdapat dua provinsi yang sudah melampaui target renstra 2018. ${ }^{1}$ Menurut Permenkes No. 88 Tahun 2012 tentang standar tablet darah bagi wanita usia subur dan ibu hamil, suplemen zat besi dapat melindungi wanita subur dan ibu hamil dari kekurangan gizi dan mencegah zat besi. ${ }^{9}$

Berdasarkan latar belakang bahwa anemia merupakan hal serius yang harus diketahui dan dicegah oleh ibu hamil maka penulis tertarik untuk mengetahui gambaran pengetahuan dan sikap ibu hamil terhadap pencegahan anemia pada kehamilan di Indonesia.

\section{METODE PENELITIAN}

Penelitian ini berbentuk suatu literature review. Proses pencarian literatur yang dalam penelitian ini diperoleh dari Pubmed, ClinicalKey, ScienceDirect, dan Google Scholar dengan kata kunci anemia AND pregnant woman AND knowledge OR attitude AND Indonesia untuk Pubmed, ClinicalKey, dan ScienceDirect, dan kata kunci anemia $A N D$ ibu hamil $A N D$ pengetahuan $A N D$ sikap untuk Google Scholar. Data yang digunakan berasal dari literatur terbitan 10 tahun terakhir yang dapat diakses full text, sesuai dengan tema literatur dan kriteria inklusi. 


\section{HASIL PENELITIAN}

Hasil pencarian literatur mendapatkan 11 literatur yang membahas mengenai pengetahuan dan sikap ibu hamil terhadap pencegahan anemia pada kehamilan. Tabel 1 memperlihatkan hasil kajian menurut pengetahuan dari masing-masing artikel yang dipergunakan dalam penelitian ini.

Tabel 2 memperlihatkan bahwa pengetahuan ibu hamil dari berbagai daerah mengenai pencegahan anemia bervariasi. Responden berpengetahuan baik dengan persentase paling tinggi terdapat di daerah Palu (62\% dari 100 responden), dan persentase terendah di daerah Rumbai $(7,4 \%$ dari 54 responden).

Tabel 3 memperlihatkan hasil bervariasi dari sikap responden ibu hamil dalam pencegahan anemia, dengan jumlah persentase tertinggi sikap positif di daerah Jepara (89,9\% dari 69 responden), dan jumlah persentase terendah sikap positif di daerah Rumbai (22,2\% dari 54 responden).

Tabel 1. Hasil kajian dari masing-masing literatur yang digunakan dalam penelitian ini

\begin{tabular}{|c|c|c|c|}
\hline Peneliti & Tujuan & Jenis penelitian & $\begin{array}{c}\text { Jumlah res- } \\
\text { ponden/sampel }\end{array}$ \\
\hline $\begin{array}{l}\text { Safitri et al, } \\
2017^{10}\end{array}$ & $\begin{array}{l}\text { Untuk menggambarkan atau mendeskripsikan } \\
\text { fenomena mengenai gambaran pengetahuan } \\
\text { dan sikap ibu hamil tentang kebutuhan tablet } \\
\text { besi selama kehamilan di Puskesmas RBI. }\end{array}$ & $\begin{array}{l}\text { Penelitian bersifat } \\
\text { deskriptif, dengan } \\
\text { pendekatan cross } \\
\text { sectional }\end{array}$ & 31 responden \\
\hline $\begin{array}{l}\text { Prapitasari E, } \\
2013^{11}\end{array}$ & $\begin{array}{l}\text { Untuk mengetahui hubungan antara } \\
\text { pengetahuan tingkat anemia dan sikap ibu } \\
\text { hamil dalam mengonsumsi tablet Fe dengan } \\
\text { anemia pada ibu hamil di Puskesmas Kerjo } \\
\text { Kabupaten Karanganyar }\end{array}$ & $\begin{array}{l}\text { Penelitian observa- } \\
\text { analitik dengan } \\
\text { pendekatan cross } \\
\text { sectional }\end{array}$ & 49 responden \\
\hline $\begin{array}{l}\text { Angriany R, } \\
2016^{12}\end{array}$ & $\begin{array}{l}\text { Untuk mengetahui hubungan pengetahuan } \\
\text { dengan sikap ibu hamil dalam pencegahan } \\
\text { anemia kehamilan. }\end{array}$ & $\begin{array}{l}\text { Penelitian analitik } \\
\text { kuantitatif dengan } \\
\text { rancangan penelitian } \\
\text { cross sectional. }\end{array}$ & 54 responden \\
\hline $\begin{array}{l}\text { Sulistiyanti P, } \\
2015^{13}\end{array}$ & $\begin{array}{l}\text { Untuk mengetahui tingkat pengetahuan ibu } \\
\text { hamil tentang anemia, untuk mengetahui } \\
\text { kepatuhan konsumsi tablet Fe pada ibu hamil, } \\
\text { dan untuk menganalisis hubungan tingkat } \\
\text { pengetahuan ibu hamil tentang anemia dengan } \\
\text { kepatuhan konsumsi tablet Fe di wilayah kerja } \\
\text { Puskesmas Masaran I Sragen. }\end{array}$ & $\begin{array}{l}\text { Penelitian analitik } \\
\text { korelasional dengan } \\
\text { pendekatan cross } \\
\text { sectional. }\end{array}$ & 50 responden \\
\hline $\begin{array}{l}\text { Soraya M, } \\
2013^{14}\end{array}$ & $\begin{array}{l}\text { Untuk mengetahui hubungan pengetahuan } \\
\text { tentang anemia pada ibu hamil dengan } \\
\text { kepatuhan dalam mengonsumsi tablet besi. }\end{array}$ & $\begin{array}{l}\text { Penelitian analitik } \\
\text { katagorik tidak } \\
\text { berpasangan, dengan } \\
\text { desain studi cross } \\
\text { sectional. }\end{array}$ & 69 responden \\
\hline $\begin{array}{l}\text { Wulandini P } \\
\text { dan Triska T, } \\
2017^{15}\end{array}$ & $\begin{array}{l}\text { Untuk mengetahui hubungan pengetahuan ibu } \\
\text { hamil tentang anemia dengan kepatuhan } \\
\text { mengonsumsi tablet Fe. }\end{array}$ & $\begin{array}{l}\text { Penelitian korelasi } \\
\text { dengan pendekatan } \\
\text { cross sectional. }\end{array}$ & 66 responden \\
\hline $\begin{array}{l}\text { Fatimah et al, } \\
2016^{16}\end{array}$ & $\begin{array}{l}\text { Untuk mengetahui tingkat pengetahuan ibu } \\
\text { hamil tentang anemia dalam kehamilan } \\
\text { terhadap perilaku konsumsi suplemen zat besi } \\
\text { di wilayah kerja Puskesmas Talise. }\end{array}$ & $\begin{array}{l}\text { Penelitian analitik dan } \\
\text { observasional dengan } \\
\text { pendekatan cross } \\
\text { sectional }\end{array}$ & 100 responden \\
\hline $\begin{array}{l}\text { Parapat F, } \\
2019^{17}\end{array}$ & $\begin{array}{l}\text { Untuk mengetahui sejauh mana pengetahuan } \\
\text { dan sikap ibu hamil terhadap pencegahan } \\
\text { anemia defisiensi besi. }\end{array}$ & $\begin{array}{l}\text { Penelitian kuantitatif } \\
\text { dengan desain des- } \\
\text { kriptif dan pendekatan } \\
\text { cross sectional }\end{array}$ & 50 responden \\
\hline $\begin{array}{l}\text { Putri D, } \\
2018^{18}\end{array}$ & $\begin{array}{l}\text { Untuk mengetahui bagaimana hubungan } \\
\text { pengetahuan dan sikap ibu hamil trimester III } \\
\text { dalam mengonsumsi tablet Fe dengan } \\
\text { terjadinya anemia di BPM Mardiani Ilyas } \\
\text { Aceh Tahun } 2018\end{array}$ & $\begin{array}{l}\text { Jenis survei analitik, } \\
\text { dengan pendekatan } \\
\text { cross sectional. }\end{array}$ & 31 responden \\
\hline
\end{tabular}


Fauziah D, Untuk mengetahui hubungan

$2017^{19} \quad$ pengetahuan dan sikap ibu hamil tentang

anemia dengan kejadian anemia di

Wilayah Kerja Puskesmas Singaparna

Kecamatan Singaparna Kabupaten

Tasikmalaya tahun 2017.

Juniliyanti H, Untuk mengetahui hubungan pengetahuan dan $2017^{20}$ kap ibu tentang anemia dengan kejadian
Jenis survei

analitik, dengan

pendekatan cross

sectional

Penelitian analitik dengan rancangan cross sectional.
35 responden

46 responden anemia dalam kehamilan di wilayah kerja puskesmas Kandai Kota Kendari tahun 2017

Tabel 2. Hasil kajian menurut pengetahuan pada masing-masing literatur

\begin{tabular}{|c|c|c|c|c|c|c|c|c|c|}
\hline \multirow{3}{*}{ Peneliti } & \multirow{3}{*}{$\begin{array}{c}\text { Lokasi } \\
\text { penelitian }\end{array}$} & \multicolumn{6}{|c|}{ Pengetahuan } & \multicolumn{2}{|c|}{ Total } \\
\hline & & \multicolumn{2}{|c|}{ Baik } & \multicolumn{2}{|c|}{ Cukup } & \multicolumn{2}{|c|}{ Kurang } & & \\
\hline & & $\mathrm{N}$ & $\%$ & $\mathrm{~N}$ & $\%$ & $\mathrm{~N}$ & $\%$ & $\mathrm{~N}$ & $\%$ \\
\hline Safitri et $\mathrm{al}^{10}$ & $\begin{array}{l}\text { Bandar } \\
\text { Lampung }\end{array}$ & 3 & 9,6 & 23 & 74,2 & 5 & 16,2 & 31 & 100 \\
\hline Prapitasari $E^{11}$ & Karanganyar & 19 & 38,8 & 25 & 51 & 5 & 10,2 & 49 & 100 \\
\hline Angriany $R^{12}$ & Rumbai & 4 & 7,4 & 18 & 33,3 & 32 & 59,3 & 54 & 100 \\
\hline Sulistiyanti $\mathrm{A}^{13}$ & Sragen & 12 & 24 & 13 & 26 & 25 & 50 & 50 & 100 \\
\hline Soraya $\mathrm{M}^{14}$ & Jepara & 28 & 40,6 & 32 & 46,4 & 9 & 13 & 69 & 100 \\
\hline $\begin{array}{l}\text { Wulandini P dan } \\
{\text { Triska } T^{15}}\end{array}$ & Pekanbaru & 11 & 16,7 & 18 & 27,3 & 37 & 56,1 & 66 & 100 \\
\hline Fatimah et al ${ }^{16}$ & Palu & 62 & 62 & 28 & 28 & 10 & 10 & 100 & 100 \\
\hline Parapat $\mathrm{F}^{17}$ & Medan & 14 & 28 & 26 & 52 & 10 & 20 & 50 & 100 \\
\hline Putri $\mathrm{D}^{18}$ & Aceh & 4 & 12,9 & 6 & 19,35 & 21 & 67,75 & 31 & 100 \\
\hline Fauziah $\mathrm{D}^{19}$ & Tasikmalaya & 12 & 34,3 & 21 & 60 & 2 & 5,7 & 35 & 100 \\
\hline Juniliyanti $\mathrm{H}^{20}$ & Kendari & 20 & 43,5 & 8 & 17,4 & 18 & 39,1 & 46 & 100 \\
\hline
\end{tabular}

Tabel 3. Hasil kajian menurut sikap dari masing-masing literatur

\begin{tabular}{|c|c|c|c|c|c|c|c|}
\hline \multirow[t]{3}{*}{ Peneliti } & \multirow[t]{3}{*}{ Lokasi penelitian } & \multicolumn{4}{|c|}{ Sikap } & \multicolumn{2}{|c|}{ Total } \\
\hline & & \multicolumn{2}{|c|}{ Positif } & \multicolumn{2}{|c|}{ Negatif } & \multirow[b]{2}{*}{$\mathrm{N}$} & \multirow[b]{2}{*}{$\%$} \\
\hline & & $\mathrm{N}$ & $\%$ & $\mathrm{~N}$ & $\%$ & & \\
\hline Safitri et a ${ }^{10}$ & Bandar Lampung & 19 & 61,3 & 12 & 38,7 & 31 & 100 \\
\hline Prapitasari $E^{11}$ & Karanganyar & 44 & 89,8 & 5 & 10,2 & 49 & 100 \\
\hline Angriany $\mathrm{R}^{12}$ & Rumbai & 12 & 22,2 & 42 & 77,8 & 54 & 100 \\
\hline Sulistiyanti $\mathrm{A}^{13}$ & Sragen & 12 & 24 & 38 & 76 & 50 & 100 \\
\hline Soraya $\mathrm{M}^{14}$ & Jepara & 62 & 89,9 & 7 & 10,1 & 69 & 100 \\
\hline $\begin{array}{l}\text { Wulandini P dan } \\
\text { Triska } T^{15}\end{array}$ & Pekanbaru & 33 & 50 & 33 & 50 & 66 & 100 \\
\hline Fatimah et $\mathrm{al}^{16}$ & Palu & 77 & 77 & 23 & 23 & 100 & 100 \\
\hline Parapat $\mathrm{F}^{17}$ & Medan & 43 & 86 & 7 & 14 & 50 & 100 \\
\hline Putri $\mathrm{D}^{18}$ & Aceh & 10 & 32,3 & 21 & 67,7 & 31 & 100 \\
\hline Fauziah $D^{19}$ & Tasikmalaya & 20 & 57,1 & 15 & 42,9 & 35 & 100 \\
\hline Juniliyanti $\mathrm{H}^{20}$ & Kendari & 28 & 60,9 & 18 & 39,1 & 46 & 100 \\
\hline
\end{tabular}




\section{BAHASAN \\ Pengetahuan ibu hamil tentang anemia pada kehamilan}

Anemia masih menjadi masalah kesehatan global yang serius, terutama pada ibu hamil. ${ }^{2}$ Pengetahuan ibu hamil mengenai anemia dapat membantu mencegah anemia selama kehamilan. Berdasarkan 11 literatur yang telah didapatkan, lima hasil penelitian menunjukkan mayoritas ibu hamil memiliki pengetahuan cukup, empat literatur lainnya menunjukkan hasil pengetahuan buruk, sedangkan hasil dengan pengetahuan baik didapatkan pada dua literatur.

Beberapa faktor, baik internal seperti jasmani dan rohani atau eksternal, seperti jenis kelamin, usia, pekerjaan, paritas, pendidikan, pengalaman, hubungan sosial, ekonomi, dan informasi dapat memengaruhi pengetahuan seseorang. ${ }^{21}$ Perbedaan dari hasil penelitian ini dapat dipengaruhi oleh usia, perbedaan status sosialekonomi, budaya, juga kepercayaan mengenai kebutuhan gizi dan gaya hidup yang sehat dari berbagai daerah. ${ }^{14}$

Tingkat pendidikan juga dapat meningkatkan kesadaran, memengaruhi proses berpikir, dan membentuk pola pikir, sehingga ibu hamil dapat dengan mudah memperoleh informasi dan pengetahuan. $^{22}$ Dari 11 literatur yang diteliti, responden penelitian dari Angriany, ${ }^{12}$ Sulistiyanti, ${ }^{13}$ Soraya, ${ }^{14}$ dan Juniliyanti, ${ }^{20}$ mayoritas berpendidikan tamatan sekolah menengah; responden dari penelitian Fatimah, ${ }^{16}$ dan Putri, ${ }^{18}$ mayoritas tamatan sekolah menengah atas; dan responden penelitian Prapitasari ${ }^{11}$ mayoritas tamatan sekolah dasar, sedangkan penelitian dari Safitri et al, ${ }^{10}$ Wulandini dan Triska, ${ }^{15}$ Parapat, ${ }^{17}$ dan Fauziah, ${ }^{19}$ tidak mencantumkan karakteristik subjek pada artikelnya. Dihubungkan dengan hasil dari penelitian menunjukkan mayoritas hasil penelitian cukup dan rendah, pendidikan dapat menjadi salah satu faktor yang memengaruhi hasil penelitian ini. Hal ini sejalan dengan penelitian dari Stephen et $\mathrm{al}^{23}$ di Tanzania mengenai prevalensi, faktor risiko, dan akibat perinatal dari anemia pada kehamilan. Hasil penelitian tersebut melaporkan bahwa tingkat pendidikan rendah pada perempuan merupakan faktor independen terkait dengan anemia selama kehamilan.

Dari penelitian yang didapatkan, pekerjaan dari responden hampir seluruhnya tidak bekerja atau ibu rumah tangga, sedangkan penelitian dari Safitri et al, ${ }^{10}$ Wulandini dan Triska, ${ }^{15}$ Parapat, ${ }^{17}$ Putri, ${ }^{18}$ dan Fauziah ${ }^{19}$ tidak mencantumkan pekerjaan responden. Hal tersebut sejalan dengan penelitian oleh Maeza et $\mathrm{al}^{24}$ di Etiopia Selatan mengenai prevalensi anemia dan faktor yang berhubungan dengan ibu hamil. Penelitiannya melaporkan, status sosioekonomi dari ibu hamil berhubungan bermakna dengan anemia pada kehamilan. Wanita dari kalangan sosioekonomi rendah memiliki prevalensi anemia lebih tinggi daripada wanita dari kalangan sosioekonomi tinggi. Hal ini mungkin disebabkan karena wanita dari kalangan sosioekonomi rendah, cenderung tidak mengonsumsi makanan dengan kualitas yang baik serta kuantitas yang cukup. Penelitian dari Fantahun et al ${ }^{25}$ di Etiopia mengenai determinan sosioekonomi terhadap anemia pada kehamilan, juga melaporkan bahwa tingkat pendidikan dan status pekerjaan dari ibu hamil diindikasikan memiliki hubungan bermakna dengan anemia pada kehamilan.

Ibu hamil dengan pengetahuan yang kurang cenderung akan mengabaikan kesehatannya dan dapat melakukan hal-hal yang tidak sengaja membahayakan diri sendiri dan janinnya. Hal ini akan memburuk dengan kurangnya informasi yang didapatkan sebelum dan selama kehamilan karena adanya pemikiran dan anggapan yang salah mengenai anemia pada kehamilan dan halhal yang menyertai. ${ }^{20}$

Jika pengetahuan ibu hamil mengenai anemia baik, ibu dapat lebih mengerti halhal yang dapat menunjang kualitas kehamilan, memilih bahan makanan dan konsumsi suplemen yang dapat mencegah kondisi yang mengancam ibu dan bayi seperti anemia. Pengetahuan mengenai anemia dan pencegahannya merupakan langkah awal dalam menanggulangi anemia pada diri sendiri. ${ }^{16}$ Hal ini juga sejalan dengan penelitian dari Sunuwar et $\mathrm{al},{ }^{26}$ mengenai efek edukasi nutrisi terhadap 
tingkat hemoglobin pada wanita hamil. Penelitian tersebut melaporkan bahwa ibu hamil yang diberikan intervensi edukasi mengenai nutrisi, anemia, dan diet berbasis makanan kaya zat besi, memiliki perubahan kadar hemoglobin secara bermakna yang tinggi, peningkatan asupan makanan, dan pengetahuan gizi mengenai anemia dan makanan kaya zat besi.

Terdapat beberapa hal yang dapat membantu ibu hamil meningkatkan pengetahuannya mengenai anemia. Penelitian dari Vernissa et $\mathrm{al}^{27}$ melaporkan bahwa penggunaan leaflet dan konseling ternyata efektif meningkatkan kepatuhan ibu hamil untuk mengonsumsi tablet besi.

\section{Sikap ibu hamil tentang pencegahan anemia pada kehamilan}

Sikap merupakan bentuk dari kesiapan, kesediaan untuk bertindak, atau predisposisi perilaku (tindakan) dari seseorang. ${ }^{28}$ Dari 11 literatur yang didapatkan, tujuh literatur mendapat hasil sikap positif, tiga literatur mendapat hasil sikap negatif, dan satu literatur mendapat hasil yang sama banyak pada sikap positif dan negatif. Hasil tersebut menunjukkan, mayoritas daerah di Indonesia memiliki sikap positif dalam pencegahan anemia seperti rutin melakukan pemeriksaan kehamilan namun masih kurang dalam mengonsumsi makanan yang bergizi.

Penelitian dari Wulandini dan Triska ${ }^{15}$ melaporkan bahwa ibu hamil yang tidak bekerja atau ibu rumah tangga, memiliki tingkat kepatuhan yang tinggi terhadap mengonsumsi tablet besi (Fe) dibandingkan ibu hamil yang bekerja. Hal tersebut dikarenakan ibu hamil yang tidak bekerja atau ibu rumah tangga, memiliki waktu dan kesempatan yang lebih banyak untuk memeriksakan kehamilan dan mendapat tablet $\mathrm{Fe}$ dibandingkan dengan ibu yang bekerja.

Mayoritas ibu hamil yang tidak teratur mengonsumsi tablet besi $(\mathrm{Fe})$, beralasan bosan mengonsumsi setiap hari, tidak tahan dengan efek dari tablet besi yang diyakini dapat muncul seperti mual, muntah, konstipasi, diare, dan rasa tidak enak pada perut. ${ }^{14}$

Sikap ibu hamil dalam pencegahan anemia dapat dipengaruhi oleh pengalaman pribadi, juga dapat dipengaruhi oleh pengalaman orang lain atau situasi lingkungan sekitar, budaya, media massa, lembaga keagamaan atau pendidikan, serta emosional. ${ }^{19}$ Dukungan dan peran aktif dari keluarga dan lingkungan ibu hamil, membantu dalam pengawasan kesehatan selama kehamilan, sekaligus dapat melakukan tindakan yang benar saat ditemukan masalah kesehatan pada ibu hamil.

Perilaku seseorang banyak terpengaruh dari orang yang dianggap penting. ${ }^{14}$ Kepercayaan terhadap orang-orang yang penting seperti tenaga medis, dapat membuat ibu hamil lebih yakin dan patuh melakukan apa yang dikatakan tenaga medis sehingga timbul kepatuhan dalam mengonsumsi tablet besi (Fe).

\section{SIMPULAN}

Mayoritas ibu hamil di beberapa daerah di Indonesia memiliki pengetahuan cukup tentang anemia dan pencegahannya seperti kepatuhan mengonsumsi tablet $\mathrm{Fe}$. Hal tersebut sebagian besar dipengaruhi oleh rendahnya sosioekonomi seperti tingkat pendidikan ibu hamil sehingga kurang mendapatkan informasi mengenai anemia.

Mayoritas ibu hamil di beberapa daerah di Indonesia sudah memiliki sikap positif terhadap pencegahan anemia pada kehamilan.

\section{Konflik Kepentingan}

Penulis menyatakan tidak terdapat konflik kepentingan dalam studi ini.

\section{DAFTAR PUSTAKA}

1. Kemenkes RI. Profil Kesehatan Indonesia 2018 [Indonesia Health Profile 2018] [Internet]. 2019; p. 207. Available from: http://www.depkes.go.id/resources/ download/pusdatin/profil-kesehatanindonesia/Data-dan-Informasi_ProfilKesehatan-Indonesia-2018.pdf

2.WHO. anaemia@www.who.int [Internet]. Available from: https://www.who.int/ health-topics/anaemia\#tab=tab_1

3. Priyanto LD. The relationship of age, educational background, and physical activity on female students with anemia. J Berk Epidemiol. 2018;6(2):139.

4. Rachmaniar R, Nelasari H, Widiwanto B, 
Kedokteran F, Muhammadiyah U. Hubungan antara pengetahuan tentang anemia pada ibu hamil trimester II dan III dengan resiko terjadinya anemia dalam kehamilan di Puskesmas Sukorame Kediri. Saintika Medika. 2013; 9(2):99-101.

5. Khuu G, Dika C. Iron deficiency anemia in pregnant women. Nurse Pract. 2017; 42(10):42-7. Available from: https:// journals.lww.com/tnpj/Fulltext/2017/10 000/Iron_deficiency_anemia_in_pregn ant_women.8.aspx

6. Soma-Pillay P, Nelson-Piercy C, Tolppanen H, Mebazaa A. Physiological changes in pregnancy. Cardiovasc J Afr. 2016; 27(2):89-94.

7. de Haas S, Ghossein-Doha C, van Kuijk SMJ, van Drongelen J, Spaanderman MEA. Physiological adaptation of maternal plasma volume during pregnancy: a systematic review and meta-analysis. Ultrasound Obstet Gynecol Off J Int Soc Ultrasound Obstet Gynecol. 2017; 49(2):177-87.

8. Anggraini DD. Faktor predisposisi ibu hamil dan pengaruhnya terhadap kepatuhan mengkonsumsi tablet besi (FE) dan anemia pada ibu hamil. Str J Ilm Kesehat. 2018;7(1):9-22.

9. Septiani W. Pelaksanaan program pemberian tablet zat besi $(\mathrm{Fe})$ pada ibu hamil. J Midwifery Sci. 2017;1(2):86-92.

10. Safitri O, Pratiwi AE, Istiqomah I. Gambaran pengetahuan dan sikap ibu hamil tentang kebutuhan tablet zat besi selama kehamilan. J Ilmu Kebidanan. 2018;2-7. Available from: http://jurnal.adila.ac.id/ index.php/jik/article/view/22

11. Prapitasari E. Hubungan antara tingkat pengetahuan anemia dan sikap ibu hamil dalam mengkonsumsi tablet $\mathrm{Fe}$ dengan kejadian anemia di wilayah kerja Puskesmas Kerjo Kabupaten Karanganyar [Skripsi Tesis]. Surakarta: Universitas Muhammadiyah Surakarta; 2013.

12. Angrainy R. Hubungan pengetahuan dengan sikap ibu hamil dalam pencegahan anemia pada kehamilan di Puskesmas Rumbai Bukit Tahun 2016. J Endur. 2017;2(1):62.

13. Sulistiyanti A. Hubungan tingkat pengetahuan ibu hamil tentang anemia dengan kepatuhan konsumsi tablet $\mathrm{Fe} \mathrm{Di}$ wilayah kerja Puskesmas Masaran I
Sragen. J Kebidanan dan Ilmu Kesehat. 2015;2(2):8-22.

14. Soraya MN. Hubungan anemia pada ibu hamil dengan kepatuhan dalam mengkonsumsi tablet besi (Fe) di Puskesmas Keling II Kabupaten Jepara. Jakarta: Universitas Islam Negri Syarif Hidayatullah; 2013. Available from: http:// repository.uinjkt.ac.id/dspace.pdf

15. Wulandari SP, Triska T. Hubungan pengetahuan ibu hamil tentang anemia dengan kepatuhan mengkonsumsi tablet $\mathrm{Fe}$ di wilayah puskesmas RI Karya Wanita Pekanbaru tahun 2017. J Matern Neonatal. 2018;2(5):300-8.

16. Fatimah WN, Widajadnya IN, Soemardji WM. Hubungan tingkat pengetahuan ibu hamil tentang anemia dalam kehamilann terhadap perilaku konsumsi suplemen zat Besi di wilayah kerja Puskesmas Talise. J Ilm Kedokt. 2019;6(1):1-8.

17. Parapat FM. Pengetahuan dan sikap ibu hamil trimester III terhadap pencegahan anemia defisiensi zat besi. J Matern Kebidanan. 2020;5(1):14-20.

18. Putri DK. Hubungan pengetahuan dan sikap ibu hamil trimester III dalam konsumsi tablet Fe dengan terjadinya anemia di BPM Mardiani Ilyas Aceh tahun 2018. J Midwifery Updat. 2019;1(1):47.

19. Fauziah D. Hubungan pengetahuan dan sikap ibu hamil tentang anemia dengan kejadian anemia di wilayah kerja Puskesmas Singaparna Kecamatan Singaparna Kabupaten Tasikmalaya tahun 2017. J Bidkesmas. 2014;2:20-9.

20. Juniliyanti $H$. Hubungan pengetahuan dan sikap ibu tentang anemia di wilayah kerja Puskesmas Kandai Kota Kendari tahun 2017 Jurusan Kebidanan Prodi DIV; 2017: p. 1-78.

21. Notoatmodjo S. Promosi Kesehatan, Teori \& Aplikasi (ed. revisi 2010). Jakarta: Rineka Cipta, 2010.

22. Ari MYD, Sulistianingsih A, Keisnawati. Faktor-faktor terjadinya anemia pada ibu primigravida di wilayah kerja Puskesmas Pringsewu Lampung. J Keperawatan. 2015;6(2):79-87. Available from: http:// download.portal garuda.org/article.php? article $=424747 \&$ val $=278 \&$ title $=$ FAKT OR-FAKTOR TERJADINYA ANEMIA PADA IBU PRIMIGRAVIDA DI WILAYAH KERJA PUSKESMAS PRINGSEWU LAMPUNG 
23. Stephen G, Mgongo M, Hussein Hashim T, Katanga J, Stray-Pedersen B, Msuya SE. Anaemia in pregnancy: prevalence, risk factors, and adverse perinatal outcomes in Northern Tanzania. Anemia. 2018; 2018.

24. Lebso M, Anato A, Loha E. Prevalence of anemia and associated factors among pregnant women in Southern Ethiopia: a community based cross-sectional study. PLoS One. 2017;12(12):1-11.

25. Mekonnen FA, Ambaw YA, Neri GT. Socioeconomic determinants of anemia in pregnancy in North Shoa Zone, Ethiopia. PLoS One. 2018;13(8):1-9.

26. Sunuwar DR, Sangroula RK, Shakya NS,
Yadav R, Chaudhary NK, Pradhan PMS. Effect of nutrition education on hemoglobin level in pregnant women: A quasi-experimental study. PLoS One. 2019;14(3):1-12.

27. Vernissa V, Andrajati R, Supardi S. Efektivitas leaflet dan konseling terhadap kepatuhan minum tablet besi dan kadar hemoglobin ibu hamil dengan anemia di Puskesmas di Kabupaten Bogor. Media Penelit dan Pengemb Kesehat. 2017; 27(4):229-36.

28. Notoatmodjo S. Promosi Kesehatan dan Perilaku Kesehatan (edisi revisi 2012). Jakarta: Rineka Cipta, 2012. 